\title{
DYNAMIC TENSILE-FAILURE-INDUCED VELOCITY DEFICITS IN ROCK
}

\author{
Allan M. Rubin* and Thomas J. Ahrens ${ }^{+}$ \\ Lindhurst Laboratory of Experimental Geophysics, Seismological Laboratory, Caltech, Pasadena, Ca 91125
}

\begin{abstract}
Planar impact experiments were employed to induce dynamic tensile failure in Bedford limestone. Rock discs were impacted with aluminum and polymethyl methacralate (PMMA) flyer plates at velocities of 10 to $25 \mathrm{~m} / \mathrm{s}$. Tensile stress magnitudes and duration were chosen so as to induce a range of microcrack growth insufficient to cause complete spalling of the samples. Ultrasonic P- and S-wave velocities of recovered targets were compared to the velocities prior to impact. Velocity reduction, and by inference microcrack production, occurred in samples subjected to stresses above $35 \mathrm{MPa}$ in the $1.3 \mu$ s PMMA experiments and $60 \mathrm{MPa}$ in the $0.5 \mu \mathrm{s}$ aluminum experiments. Using a simple model for the time-dependent stress-intensity factor at the tips of existing flaws, apparent fracture toughnesses of 2.4 and 2.5 $\mathrm{MPa} \mathrm{m}^{1 / 2}$ are computed for the 1.3 and $0.5 \mu$ s experiments. These are a factor of -2 to 3 greater than quasi-static values. The greater dynamic fracture toughness observed may result from microcrack interaction during tensile failure. Data for water-saturated and dry targets are indistinguishable.
\end{abstract}

\section{Introduction}

The dynamic tensile strength of rock can exceed the quasistatic tensile strength by an order of magnitude [Rinehart, 1965]. By "dynamic tensile strength" we mean the peak transient stress sustained during high strain-rate tensile failure. The difference between dynamic and quasi-static (hereafter termed static) tensile failure results from the pristine rock containing abundant inherent flaws (pores, grain boundary cracks, etc.). If a tensile strain (stress) is increased gradually, the largest well-oriented flaw grows at the expense of others (Figure 1a). A characteristic "tensile strength" implies that the material has a characteristic largest flaw size. If the strain (stress) is increased very rapidly, then a single flaw and the zone of reduced stress surrounding that flaw cannot propagate rapidly enough to prevent other smaller or poorly-oriented flaws from later being activated (Figure 1b).

The reduction in elastic modulus concurrent with microcrack growth is an essential element in describing the deformation history (e.g., [Grady and Kipp, 1987; Shockey et al., 1974]).

The purpose of the present experiments was to determine the modulus reduction of intact dynamically-loaded rock

\footnotetext{
- Present address: Department of Geological Sciences, Brown University, Providence, RI 02912

+ Correspondent
}

Copyright 1991 by the American Geophysical Union.

Paper number 91GL00214

$0094-8534 / 91 / 91 \mathrm{GL}-00214 \$ 03.00$
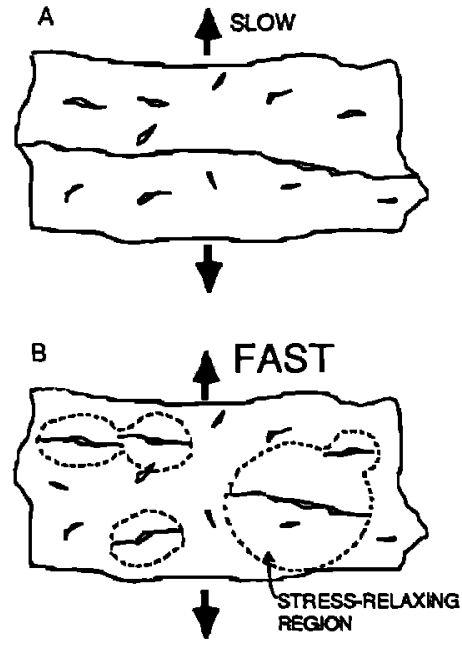

Fig. 1. Schematic diagram of tensile failure of rock under quasi-static (A) and dynamic (B) loads.

samples at various stages of crack growth. This was accomplished by (1) loading the samples with tensile stress pulses of controlled magnitude and duration insufficient to cause complete spalling, and (2) measuring the subsequent reduction in $\mathrm{P}$ - and S-wave velocity due to microcracking.

\section{Experimental Procedure}

Planar impact experiments used to produce dynamic tensile failure are described in Cohn and Ahrens [1981]. Briefly, a lexan projectile with a polymethyl methacrylate (PMMA) or aluminum (Al) flyer plate is accelerated to velocities of 10 to $25 \mathrm{~m} / \mathrm{s}$. The flyer plate impacts the target, which then flies free into a recovery tank, where loose rags prevent further damage. The target, a disc of rock $25 \mathrm{~mm}$ in diameter and 6.5 to $7.5 \mathrm{~mm}$ thick, is polished so that its front and rear surfaces are flat and parallel to $\pm 0.005 \mathrm{~mm}$. The rock selected for this study, Bedford (Indiana) limestone, has been the subject of numerous rock mechanics investigations.

Upon impact, compressive waves propagate forward into the target and back into the flyer plate. Tension is produced when these compressive waves, reflected as release waves from the free-surfaces of the target and flyer plate, later meet within the sample. The magnitude of compressive stress is proportional to the impact velocity.

Several assumptions are made in computing the magnitude and duration of the tensile pulse. (1) Because rocks are generally much stronger in compression than tension, no damage occurs during the initial compressive pulse. (2) The $\mathbf{P}$-wave velocity is constant over the pressure range involved (several tens of MPa). (3) The rise time of the stress pulse is much shorter than its duration. (4) The strain can be 
TABLE 1. Physical properties of experimental materials.

\begin{tabular}{|c|c|c|c|c|c|c|}
\hline Material & $\rho\left(\mathrm{g} / \mathrm{cm}^{3}\right)$ & $C_{p}(k m / s)$ & $\mathrm{C}_{\mathrm{s}}(\mathrm{km} / \mathrm{s})$ & $\mathrm{E}(\mathrm{GPa})$ & $\mathrm{K}_{\mathrm{IC}}(\mathrm{MPa} \sqrt{\mathrm{m}})$ & $\sigma_{\mathrm{T}}(\mathrm{MPa})$ \\
\hline $\begin{array}{l}\text { Bedford } \\
\text { limestone } \\
\text { (dry) }\end{array}$ & $2.42^{1}$ & $4.9^{1}$ & $2.8^{1}$ & $\begin{array}{l}48^{1}, 24^{2} \\
32^{3}\end{array}$ & $0.8-1.2^{4}$ & $\begin{array}{l}5.4^{2} \\
7.7^{5}\end{array}$ \\
\hline $\begin{array}{l}\text { Bedford } \\
\text { Limestone } \\
\text { (saturated) }\end{array}$ & $2.53^{1}$ & $5.1^{1}$ & \multirow{3}{*}{\multicolumn{3}{|c|}{$\begin{array}{l}\text { SOURCES } \\
\text { 1. This study } \\
\text { 2. Nur and Simmons, } 1969 \\
\text { 3. Schmidt, } 1976 \\
\text { 4. Ingraffea et al., } 1984 \\
\text { 5. Ingraffea and Schmidt, } 1978\end{array}$}} & \\
\hline PMMA & 1.2 & 2.8 & & & & \\
\hline Aluminum & 2.78 & 6.36 & & & & \\
\hline
\end{tabular}

considered to be one-dimensional. (5) Negligible crack growth occurs during later reverberations of the stress waves.

The Bedford limestone specimens used have a typical grain size of $0.5 \mathrm{~mm}$ and a porosity of $\sim 9.9 \%$ (Table 1 ). Ultrasonic velocities (reproducible to $<2 \%$ ) were measured using the travel-time method with $1 \mathrm{MHz}$ PZT transducers. Table 1 also gives previous determinations of the static tensile strength, $\sigma \mathrm{T}$, fracture toughness, $\mathrm{K}_{\mathrm{Ic}}$, and Young's modulus, E.

\section{Results and Discussion}

The results of the ultrasonic velocity measurements are shown in Figure 2. Both longitudinal- and shear-wave velocities in the direction perpendicular to the impact surface were measured, and compared to the pre-shot velocities. Important points are:

(1) Comparable levels of rock damage occur at considerably lower stresses in the longer-duration experiments.The onset of microcrack growth, as determined by a detectable reduction in sound velocity, occurs at computed stresses of $\sim 60$ and $\sim 35 \mathrm{MPa}$ in the 0.5 and $1.3 \mu \mathrm{s}$ experiments. Complete spalling occurs above computed stresses of $\sim 135$ and $60 \mathrm{MPa}$ in the 0.5 and $1.3 \mu \mathrm{s}$ experiments.

(2) Macroscopic radial cracks were produced above computed stresses of $\sim 100$ and $45 \mathrm{MPa}$ in the 0.5 and $1.3 \mu \mathrm{s}$ experiments, indicating that strain was not completely onedimensional as assumed. Such radial cracks commonly plague planar-impact recovery experiments [Shockey et al., 1974].

(3) Comparable velocity reductions occur for both longitudinal and shear waves.

(4) The results for the four water-saturated targets are indistinguishable from those for the dry targets.

\section{Interpretation of the velocity reduction data}

The P-wave velocity of the starting material was $75 \%$ of that reported by Christensen [1982] for an aggregate of calcite crystals. This implies an initial crack density of $\sim 0.2$, assuming a random distribution of penny-shaped cracks, where crack density is expressed as the number of cracks per unit volume times the average of the cube of the crack radii [O'Connell and Budiansky, 1974]. A 2\% reduction in P-wave velocity corresponds to an increase in crack density of 0.016 , or about a $3 \%$ increase in the radii of the largest cracks present, so this growth represents the minimum that could be
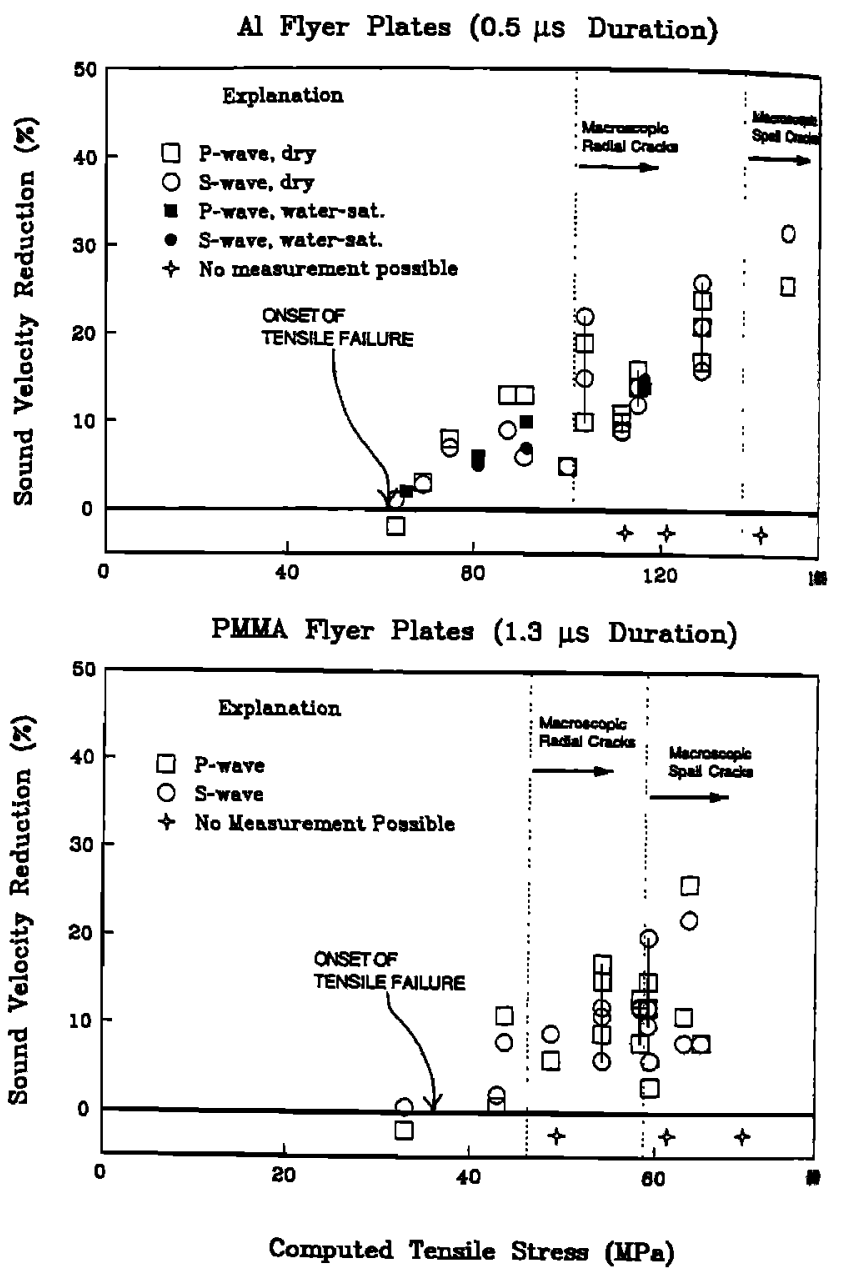

Fig. 2. Velocity measurements for $0.5 \mu \mathrm{s} \mathrm{(A)} \mathrm{and} 1.3 \mu \mathrm{s} \mathrm{(i)}$ experiments. Dashed lines indicate pressures above which macroscopic radial and impact-face-parallel (spall) cracts occurred. Vertical bars connect measurements made different pieces of targets broken by radial cracks.

detected by the present method.

\section{Onset of tensile cracking}

Following Grady and Kipp [1987], we use a simple mod for the time-dependent stress-intensity factor at the tips 4 
inherent flaws to compute an apparent fracture toughness appropriate for the dynamic loading conditions of the experiments. The assumption is that crack growth occurs when the crack-tip stress-intensity factor, $\mathrm{K}_{\mathrm{I}}$, equals the rock fracture toughness, $\mathrm{K}_{\mathrm{Ic}}$ - Under a static applied tension $\sigma$, for an isolated penny-shaped crack of radius a,

$$
K_{I}=2 \sigma \sqrt{a / \pi}
$$

Under dynamic loading conditions the form of the equation remains the same, but for early time, the "effective" crack size grows as $C_{S}$ t where $C_{S}$ is the shear-wave velocity:

$$
\mathrm{K}_{\mathrm{I}} \sim 2 \sigma \sqrt{\mathrm{C}_{\mathrm{s}} \mathrm{t} / \pi,} \quad \mathrm{C}_{\mathrm{s}} \mathrm{t}<\mathrm{a} \text {. }
$$

These considerations imply that for suddenly applied loads of a prescribed duration $t$, there is some critical tension, $\sigma$, above which $K_{I}>K_{I c}$, given sufficiently large cracks (of radius $a>C_{S} t$ ). Substituting into eq. $1 \mathrm{~b}$ the stress at the onset of microcracking for $\sigma$, the duration of the tensile pulse for $t$, and the value of $C_{S}$ for Bedford limestone, we compute $\mathrm{K}_{\mathrm{Ic}}$ ( $\mathrm{KI}_{\mathrm{I}}$ at the onset of microcracking) to be 2.4 and $2.5 \mathrm{MPa} \mathrm{m} 1 / 2$ for the 1.3 and $0.5 \mu$ s experiments, respectively. This is 2 to 3 times the 0.8 to $1.2 \mathrm{MPa} \mathrm{m}^{1 / 2}$ reported by Ingraffea et al. [1987] for Indiana limestone under static loading.

We identify two possible ways to relate the fracture toughness and initial flaw size from the present data to the static fracture toughness and grain size of Bedford limestone:

\section{(1) The computed magnitude and/or duration of the ensile loads could be overestimates.}

Grady and Kipp [1987] found typical strain rates in plate impact experiments to be $10^{4} / \mathrm{s}$. For the current Young's modulus, this would produce stresses of $60 \mathrm{MPa}$ in $0.125 \mu \mathrm{s}$. However, wave scattering due to the large porosity and grain size ( $1 / 5$ of the tensile pulse wavelength for the $0.5 \mu \mathrm{s}$ experiments) could produce further spreading of the wave front and attenuation of the peak stress.

(2) The interaction of several closely-spaced flaws could be critical in the initiation of tensile failure.

Under static loading conditions, the stress-intensity factors at the tips of closely-spaced cracks can be much larger than for the same size isolated cracks. Under dynamic loading conditions, the time required for the stress-intensity factors to reach their static values would be much longer for interacting cracks than for isolated cracks. Microcrack interaction could play an essential role in both dynamic and static rock failure.

We believe that the discrepancy between the dynamic and static data remains even for those cases cited by Grady and Kipp [1987] where the stress history has been determined more directly. The reason is that for initial crack lengths below some critical value, the "apparent" fracture toughness determined from static experiments has been found to decrease with crack length (Figure 3 ).

\section{Increasing rock damage with stress level.}

At higher tensile stress $\sigma, K_{I}$ reaches $K_{I c}$ at earlier times $t_{c}$. Rewriting eq. $1 \mathrm{~b}$, we obtain

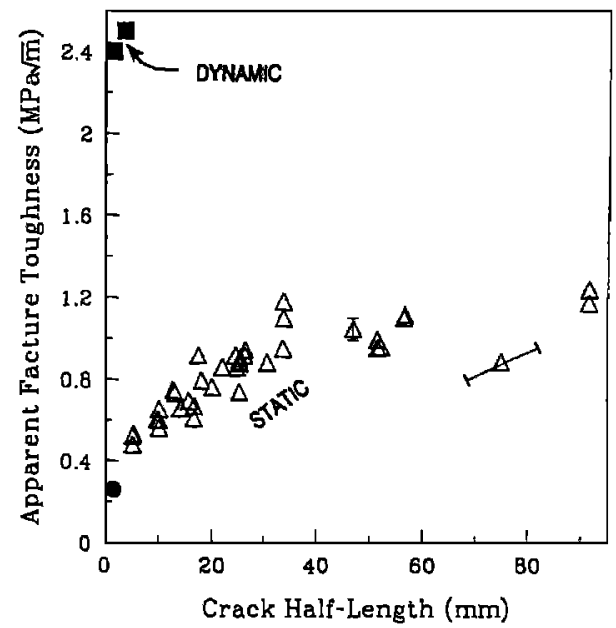

Fig. 3. Apparent quasi-static fracture toughness as a function of crack size in Bedfond limestone (modified from [Ingraffea, 1987]). Bars give standard deviation of tests. Solid circle is from static tensile tests (tensile strength $6 \mathrm{MPa}$; isolated flaws of radius $1.5 \mathrm{~mm}$ ), squares are present data (plotted at computed minimum crack length).

$$
\mathrm{t}_{\mathrm{c}}=\pi \mathrm{K}_{\mathrm{Ic}}^{2} /\left(4 \mathrm{C}_{\mathrm{s}} \sigma^{2}\right)
$$

for the time to growth. Therefore for larger $\sigma$, cracks will have a longer time in which to grow prior to the cessation of tension. In addition, crack growth at earlier times implies more cracks of radius a $>\mathrm{C}_{s} \mathrm{t}_{c}$, so more cracks will be activated. Both these factors promote increasing crack density and ultimately complete spalling. Assuming an initial crack density of 0.2 , the measured $30 \%$ reduction in sound velocity prior to complete spalling corresponds approximately to an increase in crack density to 0.4 [O'Connell and Budiansky, 1974]. At crack densities above about 0.5 the O'Connell and Budiansky model predicts that the material quickly disaggregates with increasing damage, providing a plausible explanation for our detected maximum velocity reduction. Within the interval 0.2 to 0.4 the velocity reduction increases nearly linearly with crack density, so we interpret the data as indicating increases in crack density of $0.03 / \mathrm{MPa}$ and $0.01 / \mathrm{MPa}$ in the 1.3 and $0.5 \mu$ s experiments, respectively.

The slopes of the velocity reduction vs. stress magnitude curves provide information concerning the crack population in the starting material.

The ultimate spall strength of $60 \mathrm{MPa}$ determined for the $1.3 \mu \mathrm{s}$ experiments is approximately 10 times the static tensile strength reported by Schmidt [1976], consistent with the ratio of dynamic and static strengths of other rocks. However, the amount by which the computed tensile stress exceeds the actual stress is expected to increase with impact velocity, as crack growth initiates and begins to relax the tension earlier.

Radial crack growth and sub-equal reductions in P- and Swave velocities

The radial cracks observed to form above threshold stress levels for each of the two series of experiments indicate that deformation was not restricted to uniaxial strain.

Aligned cracks are expected to produce a greater reduction in $\mathrm{P}$ - than $\mathrm{S}$-wave velocity, for a propagation direction 
perpendicular to the crack planes. If all cracks formed parallel to the target impact surface, a $20 \%$ reduction in longitudinal velocity would be associated with only a $\sim 5$ to $7 \%$ reduction in shear velocity, for reasonable crack aspect ratios [Anderson et al., 1974]. For randomly oriented cracks, a 20\% reduction in longitudinal velocity is associated with an $18 \%$ reduction in shear velocity [O'Connell and Budiansky, 1974]. Subequal reductions in $\mathbf{P}$ - and $\mathbf{S}$-wave velocities in the current experiments suggest that cracks of diverse orientations have been produced, as opposed to the dominantly face-parallel spall cracks expected. Thus both radial and face-parallel cracks are apparently contributing to the measured velocity reductions.

The effect of pure water on the dynamic tensile strength of rock is unknown. The present data indicate no significant effect of water on microcrack growth.

\section{Conclusions}

(1) Sound velocity measurements are a simple and sensitive method for determining the degree of microcracking in rock. Using the computed tensile stresses at which cracking first occurred in two series of experiments of different duration, we compute dynamic stress-intensity factors of 2.4 and $2.5 \mathrm{MPa} \mathrm{m}{ }^{1 / 2}$ in Bedford limestone. These are 2-3 times the static values, and 5 times the "apparent" static fracture toughness determined for $1 \mathrm{~cm}$ cracks.

(2) Comparable reductions in longitudinal- and shearwave velocities suggest that both radial cracks and face-parallel spall cracks are contributing to the velocity reductions.

(3) Samples impacted while water-saturated produced results indistinguishable from those impacted while dry.

Acknowledgments. Research supported under AFOSR-890547 and by National Aeronautics and Space Administration. Contribution \#4827, Division of Geological and Planetary Sciences. We thank two reviewers for comments.
References

Anderson, D. L., B. Minster, and D. Cole, The effect of oriented cracks on seismic velocities, J. Geophys. Res. 79, 4011-4015, 1974.

Christensen, N. I., Seismic velocities, in Handbook of Physical Properties of Rock. Volume 2, edited by R.S. Carmichael, pp. 345, CRC Press, Boca Raton, FL, 1982.

Cohn, S. N., and T. J. Ahrens, Dynamic tensile strength of lunar rock types, I. Geophys. Res. 86, 1794-1802, 1981.

Grady, D. E., and M. E. Kipp, Dynamic rock fragmentatioa, in Eracture Mechanics of Rock, edited by B. K. Atkinsor, pp. 534, Academic Press, London, 1987.

Ingraffea, A. R., Theory of crack initiation and propagation in rock, in Fracture Mechanics of Rock, edited by B. $K$. Atkinson, pp. 534, Academic Press, London, 1987.

O'Connell, R. J., and B. Budiansky, Seismic velocities in dry and saturated cracked solids, I. Geophys. Res. 79,5412 . 5426, 1974.

Rinehart, J. S., Dynamic fracture strength of rocks, Proceedings of the 7th Symposium on Rock Mechanics.1 205-208, 1965.

Schmidt, R. A., Fracture-toughness testing of limestone, Experimental Mechanics, 16, 161-167, 1976.

Shockey, D. A., D. R. Curran, L. Seaman, J. T. Rosenberg, and C. F. Peterson, Fragmentation of rock under dynamic loads, International Journal of Rock Mechanics and Mining Sciences. 11, 303-317, 1974.

A. M. Rubin* and T. J. Ahrens, Lindhurst Laboratory of Experimental Geophysics, Seismological Laboratory, Caltech, Pasadena, CA 91125.

*Present address: Department of Geological Sciences, Brown University, Providence, RI 02912

Received: March 27, 1990

Revised: November 5, 1990

Accepted: November 15, 1990 